\title{
Prólogo
}

\section{Educación: creación de nuevas relaciones posibles*}

\section{Carlos Calvo $^{* *}$ y Antonio Elizalde ${ }^{* * *}$}

Después de varios años e investigaciones sobre la educación y el nuevo paradigma científico hemos llegado a comprender que los gérmenes caóticos de la educación y la desescolarización están presentes en el día a día escolar, aunque ocultos, si no negados, por la cultura escolar. Debemos sacarlos a la luz y comprender su potencialidad e influencia educativa transformadora. Por muchos años buscábamos que la desescolarización de la escuela no implicara su eliminación, tal como lo propuso Illich (1985), sino su transformación. A diferencia de la mayoría de los educadores, la desescolarización nunca nos ha asustado, pues siempre la hemos entendido como una tarea simple, aunque muy compleja, pero no encontrábamos la vía. No nos sentíamos perdidos, sino extraviados buscando los criterios que nos sustentarían y orientarían en tamaña empresa.

Dado que habíamos conceptualizado a la educación como el proceso de creación de relaciones posibles y a la escolarización como el proceso de repetición de relaciones preestablecidas, la desescolarización la entendíamos como el proceso de recuperación de la capacidad de crear relaciones posibles. A pesar de ello, nos faltaba un marco teórico los suficientemente complejo y consistente para avanzar en nuestra propuesta educativa y de investigación. Hace años creíamos que las Reformas educacionales, impulsadas con determinación y esperanza, lograrían el salto cualitativo que conduciría a una "educación” de calidad. Lamentablemente la mayoría ha fracasado, pues sus logros son mínimos y poco significativos ante el esfuerzo desplegado y los recursos usados. Lo más grave es que estos hechos refuerzan los prejuicios sobre la incompetencia de los profesores para enseñar y la incapacidad de los alumnos para aprender, llegando a afirmarse que para lograr una "educación de calidad" el establecimiento educacional necesita seleccionar a sus alumnos. El estudio y la investigación nos mostró que el cambio educacional que requerimos no pasa por la implementación de una Reforma formal de la escuela, los planes y programas de estudio y las formas de evaluar. Por el contrario, debemos discontinuar el trabajo escolar desescolarizando a la escuela.

\footnotetext{
* El cuerpo de este número se ha escrito en base a la investigación FONDECYT 1080073:

"Complejidades educativas emergentes y caóticas en la escuela lineal”.

** Universidad de La Serena; La Serena, Chile. Email: carlosmcalvom@gmail.com

*** Universidad Bolivariana, Santiago, Chile. Email: aelizalde@ubolivariana.cl
} 
La escuela está en crisis. Para superarla se proponen diversas medidas y reformas escolares, cada vez más complejas, demandantes y costosas. Lamentablemente, en la mayoría de los casos solo se consiguen resultados limitados e insuficientes, lo que refuerza las profecías sobre la incapacidad de los profesores para enseñar y de los alumnos para aprender. A pesar de que las evidencias sobre los malos resultados abundan, no se cuestiona el modelo escolar vigente, aunque se objeten perspectivas teóricas y metodológicas sin que ello propicie un cambio radical y sustantivo, que alimente la esperanza en cambios significativos y duraderos.

Ante los problemas que agravan la calidad de los aprendizajes la tendencia predominante consiste en aumentar el control sobre profesores, alumnos e instituciones. Se definen estándares de desempeño y calidad (CNA) que, independiente de sus intenciones y sustentos teóricos y empíricos, tienden a complicar los procesos educativos en vez de facilitarlos, lo que estimula el engaño y el cumplimiento formal de la norma sin seguir su espíritu. Por supuesto que esto no significa descartar los estándares, sino modificar paradigmáticamente el sentido de ellos. El cambio de paradigma implica una cosmovisión diferente que transforma radicalmente nuestras concepciones, valores, referencias y relaciones. No se trata de ser conductista y cambiar a constructivista, sino de establecer un nuevo marco referencial holístico y generador de sinergia, donde el conductismo y el constructivismo se transforman en algo nuevo y ninguno sea negado por el otro. El sustento epistemológico cartesiano de la escuela no permite que el azar y la improvisación cumplan su rol educativo. Además, la escuela superficializa y complica los procesos, mientras que la educación los simplifica y complejiza. La diferencia reside en contar o no con criterios orientadores.

Es extraño que el ser humano que posee un cerebro extraordinario, que algunos señalan como la cúspide de la evolución, sea incapaz de aprender bien y con seguridad las cuatro operaciones aritméticas y no pueda leer comprensivamente después de doce años de larga escolaridad. La misma persona que no aprende en la escuela, o que lo hace con muchas dificultades, no presenta impedimentos serios cuando aprende informalmente. Esta contradicción no está resuelta en la literatura académica ni indagada con interés por los investigadores educacionales.

Esta situación es en gran medida expresión del enfoque cartesiano que conceptualiza a los procesos educativos escolarizados como si fueran lineales, ordenados, coherentes, lógicos, secuenciales y opuestos a los procesos educativos informales. La escuela diseña un mapa escolar del territorio educativo obstaculizando la mayoría de los intentos por aventurarse por los parajes ignotos y desafiantes.

En este sentido, consideramos que el fracaso escolar tiene su origen epistemológico en la concepción de enseñanza y de aprendizaje que sustenta a la escuela y no en el alumno o profesor, ni en la adecuación o pertinencia de los planes y programas de estudio. Esto no significa que no tengan responsabilidad, sino que es secundaria en relación a los criterios 
paradigmáticos que la sustentan. El fracaso se debe, entre otros, a la obsesión por la respuesta, antes que por la pregunta, con lo que inhibe, si no aniquila, la curiosidad, la propensión a aprender lúdicamente y la búsqueda de lo nuevo, de lo posible. La escuela se refugia en el carácter normativo y profetiza del fracaso escolar.

Contrariamente a lo establecido en la investigación y literatura educacional en boga y respetada en los círculos académicos y de toma de decisión, que menosprecian a los procesos educativos informales, nuestra investigación nos señala que gracias a que son caóticos, emergentes y autoorganizados poseen una complejidad y nivel de abstracción muy altos, que superan sin problemas los de la escuela.

Hemos comprobado que aprender y enseñar son procesos simples y, a la vez, complejos. Basta asombrar con un misterio para que emerja el entusiasmo y la propensión a aprender. ¿Conocemos a algún pequeño que no desee aprender en una situación lúdica genuina e inocente? El carácter lúdico implica que el educando improvisa ante las dudas y las incertidumbres que despierta su curiosidad, lo que favorece la comprensión sinérgica. El aprendizaje educativo encierra una paradoja: si es genuino, confundirá al aprendiente, haciéndole creer que no ha aprendido. Ante esto, la evaluación escolar no sabe qué hacer y termina castigando a la duda, la confusión y la ignorancia. Sin atinar a comprender que saber e ignorancia se exigen como el yin y el yang.

El educando puede sortear las dificultades en la medida que se le permita hipotetizar criterios explicativos, sin importar si son correctos o no. El que lo sean será comprobado más tarde, pero nunca al inicio de la búsqueda. Si la indagación no conlleva dudas o riesgo no hay entusiasmo. Si en toda investigación no se sabe si se comprobará la hipótesis, ¿por qué tiene que serlo en la escuela? Es altamente probable que este sea el talón de Aquiles de la escuela.

El que ha aprendido es capaz de establecer relaciones y relaciones de relaciones, de tal modo que puede explicar con sencillez un asunto complejo; en caso contrario, transforma lo simple en superficial y lo complejo en complicado. Esta distinción nos ha permitido definir a la educación como el proceso de creación de relaciones posibles, y a la escolarización, es decir, la educación dentro de la escuela, como el proceso de repetición de relaciones pre-establecidas.

La tensión entre el orden, que ha sido monopolizado por la escuela, y el caos, que lo castigan permanentemente pretendiendo su eliminación, tiene en el campo de la educación informal el carácter de proceso donde uno lleva al otro. El educando va del desorden al orden, como el día sigue a la noche. Así como no tiene sentido preguntarse qué fue primero: si la noche o el día, tampoco lo tiene saber cuál es más importante: el orden o el caos educativo. Lo fundamental es entender que si el educando está en uno se moverá hacia el otro y así mientras se mantenga formulando preguntas inocentes. 
Para conseguirlo debemos buscar la manera de simplificar la enseñanza y el aprendizaje escolar. La complejidad del aprendizaje emergerá desde la comprensión del patrón simple. Desafortunadamente, la búsqueda de la simplicidad no es el objetivo de las reformas educacionales; pareciera que se castigase al educando a aprender con dolor, como si hubiese cometido un pecado. Hay que permitirles que fortalezcan su propensión a aprender, antes que forzarlos a hacer lo que no va con la naturaleza. Se trata de dejarles fluir.

El primer artículo del Lente de aproximación, de los autores Raiza Andrade, Raizabel Méndez, y Rodrigo Martínez, presenta tres nuevas gnoseologías para la educación superior en la sociedad del conocimiento. La primera considera que la palabra escolar y la palabra de la existencia, son hoy silencio muerto, ya no silencio creativo, de allí la necesidad de desempalabrar(nos) caórdicamente La segunda postula transformar el aula disciplinaria en una aula para/de/desde la Complejidad. La tercera, afirma que el conocer en cuanto praxis de la Complejidad re-liga, se articula/desarticula y re-articula del orden - al caos - al orden, del decir y del disentir al paradojar y al metaforar, en una construcción y de-construcción de sentidos de carácter continuo y permanente. Estas estrategias son concebidas como modos de proceder, de aprender y de con-vivir, onto-trans-epistémicamente. El texto que sigue de Jorge Brower Beltramín expone sintéticamente la propuesta epistemológica de Morin, denominada pensamiento complejo, que permite esbozar una pedagogía compleja, como una modalidad de aprendizaje que puede ser asumida por el sujeto en cualquier etapa de su existencia. La pedagogía compleja se funda en una re-ubicación de los participantes implicados en este proceso, como protagonistas del mismo, considerando la complejidad propia de las múltiples variables que interactúan en el comportamiento del ser humano. Brower busca instalar este esbozo en la agenda investigativa en el ámbito de la educación, para generar un debate que lo mejore y enriquezca y contribuya así a procesos de aprendizaje en contextos comunitarios armónicos y solidarios. Germán Bula a su vez en su escrito sostiene que la educación consiste en hacer ver al educando que está constituido por y es parte de múltiples sistemas y subsistemas de índole social, ambiental y cósmica, y que la educación capaz de transformar a los individuos, las sociedades y el mundo, es la que permite percibir las conexiones ocultas entre los fenómenos, pues representa un desarrollo al mismo tiempo cognitivo, ético, emotivo y espiritual. Afirma que el egoísmo y la indiferencia no son sólo falencias morales, sino también cognitivas, y la educación tiene la posibilidad de cambiarlas para así construir un sentimiento de vínculo con la totalidad, que produce asombro, gratitud y respeto ante el milagro de la existencia.

Carlos Calvo en su artículo "Complejidades educativas emergentes y caóticas” diferencia los procesos educativos de los procesos escolares de educación y la escuela, lo cual permite entender sus características, fortalezas y limitaciones. Afirma que gran parte del fracaso escolar es atribuible a desconocer que los procesos educativos tienden a fluir autoorganizándose de manera cada vez más simple y, paradojalmente, más compleja, mientras 
que los procesos escolares se entrampan en superficialidades y complicaciones perturbando a la enseñanza e inhibiendo el aprendizaje. Por su parte, Antonio Elizalde busca indagar en aquellos imaginarios que nos dificultan resolver la paradoja inherente a todo quehacer educativo: el domesticar para liberar. Para ello incursiona en la pretensión de controlar lo incontrolable, releva la importancia de lo trivial y sugiere incursionar por caminos no transitados recuperando el papel de las neuronas espejo y de la razón cordial. Se pregunta por quien enseña a quien en el mundo actual y si es posible una educación sin historia y sin valores; y finalmente nos convoca a cuidarnos del autoritarismo en nuestras prácticas educativas. En su texto Roberto Espejo explora la idea de la complejidad en educación a partir de la crítica de Edgar Morin de la hipersimplificación de un fenómeno. En función de esto desarrolla dos ámbitos que nos llevan más allá de una comprensión didáctica de la complejidad. En un caso se considera la componente política de la educación, la cual ejemplifica con el movimiento de la critical pedagogy americana. En otro caso se considera la inclusión del aspecto afectivo en la enseñanza, a través del paradigma de la confluent education. Alfredo Ghiso indaga el sentido que la proximidad tiene con el acontecimiento, la experiencia formativa y "con lo provisorio de la vida misma.” Reflexiona desde su práctica como docente universitario, en la vivencia del educador en su actuar pedagógico reflexivo. Se aproxima mediante la observación y conceptualización a lo efímero, lo contingente, la novedad, la multiplicidad, fundamentado en principios métodológicos que dan cuenta de una iniciación en el pensar complejo. Asume los principios del pensamiento complejo, a manera de conceptos sensibilizadores para comprender la interacción educativa, sugiriendo temáticas emergentes para reflexionar e investigar.

El artículo de Violeta Glaría cuestiona los fundamentos y los razonamientos de la Economía Neoclásica. Afirma que si el conocimiento es incompleto y no hay información absoluta los contextos son determinantes para la comprensión de lo estudiado. Las esferas del conocimiento no están aisladas de allí la necesidad de la transdisciplinariedad. Desde el teorema de la incompletitud de Gödel las demostraciones matemáticas no aseguran la veracidad de los resultados ni la ausencia de subjetividad (además de haber comportamientos, como el humano, que no son reductibles a la lógica matemática). Sostiene que es necesario replantearse las comprensiones de la Economía y su enseñanza en la forma actual. Taeli Gómez Francisco señala en su texto que la educación, como proceso de formación de los seres humanos para la sociedad, se encuentra determinada por los requerimientos del ser social y que se valida sólo si mantiene coherencia con los paradigmas o bases epistemológicas de un determinado cuadro científico de mundo o imagen de éste. Argumenta desde allí que las crisis o problemas que tiene el proceso educacional actual, obedecen a un movimiento objetivo de tensiones dadas por las necesidades sociales y los obstáculos de las micro y macro relaciones de poder sustentadas en los paradigmas clásicos. Arturo Guillaumín Tostado realiza una profunda crítica a la educación actual. Adopta una visión amplia para explicar cómo la educación formal se convierte en un aliado poderoso del proyecto de la modernidad: 
el control de la naturaleza para lograr el progreso humano. Proceso que en el siglo pasado confluye en la actual globalización y una educación guiada por principios economicistas. Amplía su perspectiva para incluir no sólo la historia de la humanidad, sino también la evolución de la Tierra desde hace 4,600 millones de años. Hace así evidente la pobreza de la noción de desarrollo y de los fines actuales de la educación. Exploran asimismo conceptos como "desarrollo biosférico", "simbiosis" y “autopoiesis", con el fin de esbozar lo que podría ser una educación coevolutiva. Por su parte, Francisco Gutiérrez siguiendo parcialmente el pensamiento de Hugo Assmann, postula que se aprende durante toda la vida y mediante todas las formas de vida, coincidiendo ello con la facultad de la autoorganización de los seres vivos. Aprender resulta así un proceso donde coinciden los procesos vitales con los procesos de conocimiento. Surge de ello una biopedagogía que, asentada en el placer de aprender, está en condiciones de reencantar la educación. Para ilustrar las implicancias pedagógicas de este enfoque presenta los testimonios de cuatro vivencias de aprendizaje. Ernesto Lleras Manrique en un breve ensayo aboga por concepción de la educación como un proceso desarrollado colectivamente a partir de la realización de las "vocaciones vitales" y de la capacidad de "darse cuenta”, en todos los contextos de la vida.

En su artículo Desirêe López de Maturana sostiene que el nuevo escenario para la Educación Parvularia en Chile y principalmente su gestión pedagógica, requiere de los educadores competencias más humanas que de funcionalidad técnica para comprender cómo aprenden los niños, cómo acceden al conocimiento y qué estrategias utilizan para hacerlo. Señala lo interesante que resulta centrar la mirada en los juegos infantiles, describir el tipo de interacciones sociales y con el entorno que se producen allí para descubrir en los espacios de informalidad en que estas dimensiones lúdicas se despliegan algunas aproximaciones epistemológicas que develen aquellas prácticas adultistas que usadas en los espacios educativos formales no contribuyen a los procesos de aprendizaje de los niños. De modo similar, Silvia López de Maturana señala que gracias a las historias de vida ha sido posible entender el proceso de la profesionalización docente, develar sus principales complejidades y señalar tendencias válidas para cualquier profesor que pueden ajustarse con flexibilidad a esos patrones. La construcción analítica nos aportó luces para entender y explicar como la valoración del sentido común, la improvisación, la conciencia del cambio, la reflexión y la acción pedagógica, son elementos que hacen a un profesor un Buen Profesor. Estas características podrían ser intencionalmente promovidas en las distintas etapas de formación profesional pues tienen la cualidad de generar entusiasmo, contagio con un compromiso pedagógico, social y político por el trabajo bien hecho. A su vez, Graciela Mazorco Irureta en su artículo afirma que las reformas educativas unesconianas fracasaron. Sostiene que las pedagogías constructivistas no generaron aprendizajes de mejor calidad al no romper la contradicción sujeto-objeto y no lograron superar las limitaciones del conductismo positivista. Plantea la necesidad de superar las limitaciones de la civilización antropocéntrica pues que sólo la renuncia al antropocentrismo permitirá al individuo sentirse 
humano al mismo tiempo que árbol, estrella, río o luciérnaga, y aprender de ellos lo que tengan que decirle. Escucharlos y sentirlos despertará las potencias finitas e infinitas que duermen en sus genes desde que el ser humano integral originario fue domesticado por la racionalidad educativa y comunicacional del sistema de la no unidad. Por su parte, Maria Cândida Moraes sostiene la necesidad de repensar las cuestiones curriculares a partir de la teoría de complejidad. Trabaja para ello los conceptos de currículo y de complejidad, observando que la teorización compleja del currículo ayuda a repensarlo a partir de la pluralidad cultural, de la unidad en la diversidad, de la capacidad de producir cosas nuevas cosas a partir de procesos emergentes. De modo que la intersubjetividad y la multireferencialidad reafirman la importancia de la alteridad, de la lucha por la afirmación de las diferencias, así como de los procesos auto-eco-organizadores resultantes de los diálogos surgidos en el aula. El currículo, así entendido, se transforma en el espacio de solidaridad epistémica, de emergencia y de cambio de valores. Concluye la importancia de desarrollar, mediante las prácticas curriculares, la reforma del pensamiento propuesta por Edgar Morin, a partir de la inteligencia de complejidad, como condición fundamental para superar la fragmentación del conocimiento y encontrar soluciones acordes a la magnitud de los problemas.

Alberto Moreno en su ensayo señala que la escuela ha sido tradicionalmente el dominio de lo cognitivo. En la escuela se pregunta, casi obsesivamente: ¿tú qué sabes? No es tan frecuente escuchar esta pregunta: ¿tú qué sientes? Afirma que ello es debido a la forma tradicional de entender el proceso educativo escolar. Propone reformular el proceso educativo formal a partir de la democratización escolar, y en especial a partir de la autoorganización de los tiempos y espacios educativos. Dos aspectos centrales en le proceso de democratización escolar son la libertad para tomar decisiones de forma autónoma y la libertad como el aspecto que hace emerger un espacio de convivencia agradable y fructífera. Iván Oliva en su artículo "Breve cartografía de una disonancia epistémica: educación, complejidad y reforma” desarrolla algunas ideas asociadas al campo de la epistemología, las ciencias cognitivas y las ciencias de la educación desde una aproximación compleja. En este contexto, la noción de disonancia epistémica refiere a una interpretación crítica de algunos de los axiomas paradigmáticos que subyacen y legitiman, en sus diversos niveles y dimensiones, los modelos de desarrollo en la educación contemporánea. A su vez Ariel Quezada, propone una reflexión sobre la complejidad inherente a la dinámica de los grupos humanos, entre ellos, la interacción dentro de una sala de clases. Muestra cómo las estrategias de la planificación extrema o de la improvisación absoluta pueden tener consecuencias nefastas para los procesos educativos. Sostiene que en el punto intermedio entre el completo orden y el desorden total, se encontraría la máxima complejidad, la cual permitiría alcanzar objetivos de alto nivel. Propone finalmente utilizar simulaciones computacionales para estimar los alcances que podría tener una innovación en la interacción en aula. El último artículo de esta sección monográfica dedicada a la Educación, caos y complejidad es de la autoría colectiva de María Evelinda Santiago Jiménez, Misael Murillo Murillo, Bernardo 
Parra Vitorino y María Eugenia Lazcano Herrero, quienes afirman que la función de la educación es difundir las ventajas de vivir en sociedades democráticas, sin embargo, como está articulada a intereses políticos y económicos globalizados termina anestesiando a la sociedad para que observe en silencio el desmantelamiento de su proyecto de vida. La educación tradicional no fomenta la habilidad para leer la complejidad de esa realidad democrática y principalmente alecciona sobre las "ventajas" de la modernidad, donde la mayoría tiene como destino, ser masas de asalariados y una minoría, "heredar" la élite. Proponen que para leer esta realidad, la ciudadanía debe ser alfabetizada más allá de la mera técnica que sólo sirva para leer, memorizar y escribir manuales. Por consiguiente la alfabetización debe ser permanente, reflexiva, crítica y basada en el diálogo de saberes, y además éticamente coordinada por docentes intelectuales.

En Cartografías para el futuro se incluye un texto de Alberto Montbrun "Notas para una revisión crítica del concepto de 'poder' " y otro de María Teresa Pozzoli titulado "La curiosa quietud del paradigma (aprendizajes nómades en contextos de complejidad).

La sección Proyectos y avances de investigación incluye los siguientes artículos: "El retorno a la política: intento explicativo de la nueva preponderancia de la dimensión política en las relaciones internacionales” de Daniel Bello y Armando Di Filippo; "Los docentes en la sociedad actual: sus creencias y cogniciones pedagógicas respecto al proceso didáctico” de Claudio Díaz, Patricia Martínez, Iris Roa y María Gabriela Sanhueza; de Rodrigo Elizalde Soto "Resignificación del ocio: aportes para un aprendizaje transformacional”; de Alejandro Palafox Muñoz, Lilia Zizumbo Villarreal, Emilio Gerardo Arriaga Álvarez y Neptalí Monterroso Salvatierra "Introducción al estudio del turismo a través del materialismo cultural"; de Leonardo Piña Cabrera "Calle y escritura como espacio y campo de acción. El testimonio de Carolina María de Jesús, mujer, negra y cartonera”; y por último "Variables organizacionales y psicosociales asociadas al síndrome de burnout en trabajadores del ámbito educacional” de Mauricio Ramírez Pérez y Reinaldo Zurita Zurita.

En la sección Bosquejos para una nueva episteme se presenta un polémico artículo de Carlos Y. Valenzuela "Fundamentos del Postmodernismo y el no estar ni ahí de la Universidad en (y de) Chile.”

Se presentan en este número en la sección correspondiente las reseñas de cinco libros. Octavio Avendaño presenta El buen vivir. Una vía para el desarrollo, de Alberto Acosta y Esperanza Martínez (comp.). Antonio Elizalde reseña tres libros La generación del cambio climático global, de Manuel Guzmán Hennesy; Construyendo Interculturalidad: Pueblos Indígenas, Educación y Políticas de Identidad en América Latina, de Juliana Ströbele-Gregor, Olaf Kaltmeier y Cornelia Giebeler; y Lazer na America Latina/Tiempo libre, ocio y recreación en Latinoamérica, de Christianne Gomes, Esperanza Osorio, Leila Pinto, Rodrigo Elizalde (org.). Finalmente Iván Pincheira Torres reseña el li- 
bro El miedo. Historia de una idea política, de Corey Robin.

Este ejemplar que ponemos a vuestra disposición corresponde al número 25 de la revista Polis, lo que para una revista académica es casi como una mayoría de edad. En razón de ello decidimos hacer un volumen doble en tamaño, aunque no en numeración. Como es fácil de apreciar la convocatoria realizada a escribir sobre "Educación, caos y complejidad" tuvo un notable éxito, recibimos prácticamente el doble de artículos de lo que acostumbrábamos recibir en convocatorias anteriores, de allí entonces que esta monografía sea bastante más abundante que en el pasado. Lo anterior aunque nos ha significado muchísimo más trabajo se nos ha hecho fácil por la gran calidad de los aportes incorporados. 